\title{
An interview with the editor
}

\author{
Nicola Innes \\ Deputy Editor
}

Following the recent announcement that the Centre for Evidence-Based Dentistry is relocating to the University of Dundee Dental School's Dental Health Services Research Unit, I took the opportunity to catch up with Derek Richards, who is the Director of the Centre. Derek is internationally renowned for his expertise in evidencebased dentistry and regularly supports a range of dental evidence teaching initiatives around the world. I wanted to ask the man who helped establish the Centre for Evidence-based Dentistry almost 20 years ago, and this journal, a few questions about how he got started.

NI Derek, can you tell us a little bit about how you got interested in EvidenceBased Dentistry?

DR It all started when I was doing my speciality in dental public health training. My lead trainer, Alan Lawrence, at the time had just finished developing a regional oral health strategy with Muir Gray, at that time Regional Director of Public Health in Oxford, and they decided that now there was a specialist trainee (me) we should start the Centre for Evidence-Based Dentistry! So, I started my training, and during the 2nd week of my training programme I was taken to meet Muir Gray and David Sackett in the John Radcliffe hospital canteen and we had a discussion about evidence-based healthcare. The first thing I had to do was get trained! So I then got into the Oxford CASP (Critical Appraisal Skills Programme) and spent a lot of time working with Amanda Burls, (who is still a leading light in CASP UK Network) providing workshops teaching critical appraisal skills. We then decided to run a workshop about Evidence-Based Dentistry, to encourage the profession as a whole to get involved - this was held at Templeton College in Oxford on December $15^{\text {th }}$ 1994. It involved Bob Ireland, who was professor at Liverpool who had been working on the dental informatics project ORQUEST, Steven Rear who was then the Dean at the Faculty of General Dental Practitioners, David Sackett and myself. It was my first large public engagement experience because there were people from the Department of Health, people from the Faculty and a range of the great and good in dentistry who had been invited along. It was as part of the workshop, discussing the next steps for Evidence-Based Dentistry, that it was agreed that two of those key steps were establishing the Centre for Evidence-Based Dentistry and developing a Journal in EvidenceBased Dentistry. So those were the initial stages: we then, in 1995, invited representatives to form a steering group which included the Postgraduate Dean, Dave Sackett and Muir Gray - quite a powerful group.

NI So the Journal of Evidence-Based Dentistry came about as part of that whole process then?

DR Yes, we worked through a series of meetings with Mike Grace, who was then the Editor of the British Dental Journal, their publishers, Oxford Medical Knowledge, and ourselves to develop a plan for the journal. It initially came out as a supplement for the BDJ and the original development plan was to have two supplements a year for three years before moving to a quarterly journal. However, we heard that one of the other publishers was planning to launch an EvidenceBased Dentistry Journal, so we changed plans and the journal originally came out as a quarterly supplement to the BDJ and subsequently became a stand-alone journal, in 2000 I think, and in 2004 we applied to for it to be indexed on Medline and fortunately it was accepted, so all those things happened over a four year period. It was quite a busy time, as there is quite a lot of work involved in getting a journal together!

NI Tell me a little bit about the move now to the University of Dundee Dental School.

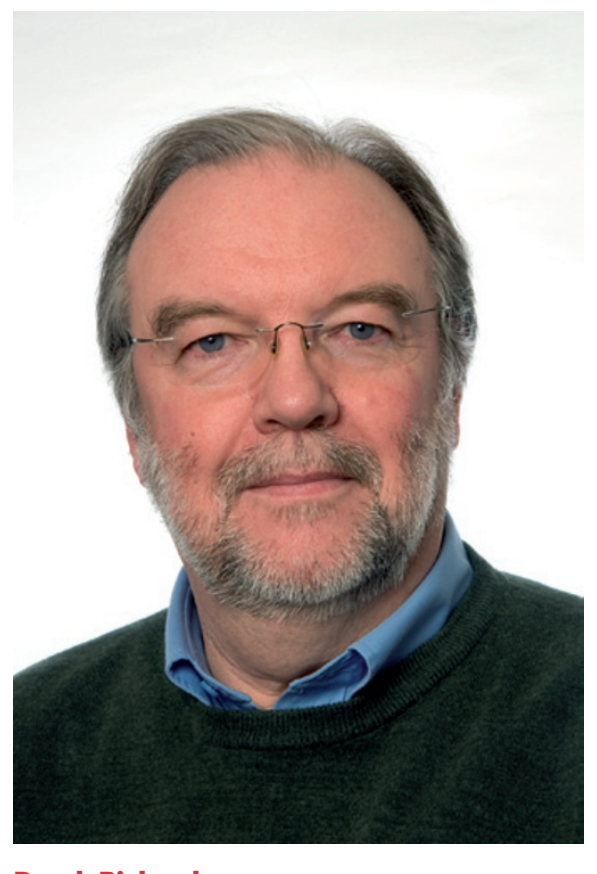

Derek Richards

DR When I was working in Oxford, after finishing my training there, I got a Consultant post in Berkshire, but we worked very closely across the Oxford region, and then because of changes within the Oxford region and in the NHS generally, I was looking for a move of post with new challenges and, having a Scottish wife, an opportunity came up in Scotland. We had a relationship with the Dental Health Services Research Unit (DHSRU) and Professor Clarkson for a number of years. We had spoken at meetings and had become quite friendly, so when the opportunity came up to move to Scotland I took it, and then shortly after moving up, I was invited to provide specialist advice to the Scottish Dental Clinical Effectiveness Programme which had only been up and running for a little while. That was one link that started to develop with Dundee, and because the Dental Health Services Research Unit and the Clinical Effectiveness Programme were two of the four evidence-based dentistry groups working in the UK (besides the Centre for Evidence-based Dentistry and, of course, the Cochrane Collaboration), we then formed a virtual network between 
the four groups. So, I've had a connection with Dundee for some time and my post in Scotland has changed around a little bit over the past four years. For my Consultant in dental public health role I now provide Dental Public Health advice and support as part of a network to the five Health Boards on the East of Scotland - that's Tayside, Forth Valley, Fife, Lothian and Borders, so the Dental School at Dundee along with DHSRU sits within NHS Tayside. Following the recent changes in the structure at Dundee Dental School an opportunity arose to move the Centre for EvidenceBased Dentistry into the School, so we took that opportunity.

NI What new developments are you making now that the Centre for EvidenceBased Dentistry has moved to the Dental School at the University of Dundee?

DR As a result of recent changes to the GDC learning outcomes for dental education, published in the Preparing for Practice document, one of the things I'll be helping with is to get more of an evidencebased focus, so although Dundee has teaching and activities around evidencebased practice interspersed throughout the five undergraduate years, some elements of my work would be to support further developments in this. Also, looking towards postgraduate developments, develop a Masters programme in Evidence-Based Health Care that has a dental focus, following on from being involved with teaching on a Masters programme in Oxford for a number of years. So it would be nice to have a more dentally focussed Masters programme in Evidence-Based Healthcare and that's one of the things we are hoping to develop in the not too distant future.

NI That sounds very exciting. I believe that you're a good friend of the Dental Elf too, aren't you?
DR I am a friend of the Dental Elf, in fact I masquerade as the Dental Elf! It's a fairly recent development - he's been going since 2011. It was an innovative idea originally from the evidence-based consultancy company called Minervation that I've been working with for a number of years. Two directors of the company, Andre Tomlin and Doug Badenoch, used to run the IT and the web presence for the Centre for Evidence-Based Medicine and the Centre for EvidenceBased Mental Health, and when funding for them dried up a number of years ago, they formed their own company. They have been responsible for the Centre for Evidence-Based Dentistry's web presence for a number of years too, so we have a long-standing relationship. They proposed the idea of the Dental Elf as part of the National Elf Service, so we have been running that now since 2011. It has a growing band of support and a growing number of followers and we have plans to develop that for the future now as well.

NI I know the Dental Elf has about 1,500 followers on Twitter (@DentalElf), and I'm sure that will also continue to grow. What do you think of the high spots within Dentistry for Evidence-Based Practice and Healthcare?

DR I suppose one of the high spots is the development and success of the Cochrane Oral Health Group which has now completed over 150 reviews. One of the disappointments though, is that, although there is a robust evidence-base for prevention, perhaps it isn't implemented to the degree that it should be, and the evidence we have is a little bit thin on the ground in other areas of Dentistry although this is improving.

NI I guess that brings me on to the next question I'd like to ask. What do you think are the areas that are going to be important in Evidence-Based Dentistry?

DR Well I think the development of the Triads Programme in Dundee is another good reason for coming here. This is a multi-disciplinary group looking at implementation of knowledge across a number of specialties now and is a very constructive development that could be taken forward further. Also, I suppose the involvement of the American Dental Association and their EvidenceBased Centre has been another positive: they have put a lot of resource into it in recent times and that is a really optimistic development. I spend some of my time travelling over to the US as we help them run an Advanced EvidenceBased Dentistry course annually and have done for the last six or seven years. A number of appointments to EvidenceBased Dentistry lecturing posts have been made too and that's another welcome achievement - although it has taken almost twenty years to get there - but change is sometimes a long and difficult process, but I feel that we are starting to make progress along the road and the future for Evidence-Based Dentistry is looking positive!

Derek, thanks for taking the time to talk a bit about how you got started in world of dental evidence. Your early lead in establishing the Centre for Evidence-Based Dentistry and the journal has promoted evidence within dentistry as an entity before most people were formally thinking this way.

"The Centre for Evidence-based Dentistry, established in 1995, is an independent body whose aim is to promote the teaching, learning, practice and evaluation of evidencebased dentistry world-wide." http://www. cebd.org/

Evidence-Based Dentistry (2013) 14, 100-101. doi:10.1038/sj.ebd.6400962 